\title{
A escuta de pais nas entrevistas preliminares com crianças: algumas questões iniciais
}

\author{
Andrea Gabriela Ferrari' \\ Universidade Federal do Rio Grande do Sul, RS, Brasil \\ Rose Gurski \\ Universidade Federal do Rio Grande do Sul, RS, Brasil \\ Milena da Rosa Silva \\ Universidade Federal do Rio Grande do Sul, RS, Brasil
}

\begin{abstract}
Resumo: Este escrito discute os efeitos da escuta de pais nas Entrevistas Preliminares da criança para o início do tratamento. Foram analisadas as entrevistas realizadas com uma mãe que pede atendimento psicológico para seu filho por queixa de hiperatividade. Parte-se do pressuposto de que, algumas vezes, o sintoma apresentado pela criança revela aspectos mal elaborados do processo de recalcamento da história infantil dos pais. Pensamos que o trabalho com quem demanda atendimento para a criança permite recompor o que de seu infantil ficou fraturado, e, a partir de uma operação de elaboração permitida pela rememoração, este possibilita que os pais autorizem a criança a demandar tratamento em nome próprio. Consideramos as Entrevistas Preliminares realizadas com os pais um dispositivo potente que permite o reposicionamento das funções parentais frente à demanda de atendimento para o filho.
\end{abstract}

Palavras-chave: entrevistas preliminares; psicanálise com crianças; início do tratamento; sintoma na criança; escuta a pais.

\section{LISTENING TO PARENTS IN PRELIMINARY INTERVIEWS WITH CHILDREN: SOME INITIAL QUESTIONS}

\begin{abstract}
This writing discusses the effects of parents listening to the Preliminary Interviews of a child at the start of treatment. Interviews with a mother who asked psychological care for her child because of complaints about hyperactivity were analyzed. We start from the hypothesis that sometimes symptoms presented by the child reveal badly elaborated aspects of the repression process of the parents' childhood. We think that working with those who ask for care for the child lets us recover what was fractured in the child's childhood and, from a development operation permitted by the child's memories, enables parents to allow the child to require treatment on their own. We consider the Preliminary Interviews with parents a powerful device that allows repositioning of parental roles in order to fulfill the demand of care for the child.
\end{abstract}

Keywords: preliminary interviews; psychoanalysis with children; start of treatment; symptom in children; listening to parents.

\section{LA ESCUCHA DE PADRES EN ENTREVISTAS PRELIMINARES CON NIÑOS: ALGUNAS CUESTIONES INICIALES}

Resumen: Este trabajo pretende discutir los efectos de la escucha de padres en Entrevistas Preliminares del niño para el inicio de su tratamiento. Para esto se analizaron las

1 Endereço para correspondência: Andrea Gabriela Ferrari, Rua Ramiro Barcelos, 2600, sala 130. CEP: $90035-$ 003. Porto Alegre, RS. E-mail: andrea.ferrari@ufrgs.br. 
entrevistas que fueron realizadas con una madre que pidió atención psicológica para su hijo por una queja de hiperactividad. Partimos de la presuposición que muchas veces el síntoma presentado por el niño manifiesta aspectos mal elaborados del proceso de represión de la historia infantil de los padres. Pensamos que el trabajo con quien demanda atención psicológica para el niño permite recomponer, por una elaboración permitida por la rememoración, lo que quedó fracturado de su propio infantil. Esto permitiría que los padres autoricen que el niño demande tratamiento por su propio nombre. Consideramos las Entrevistas Preliminares con los padres un dispositivo potente pues permite un cambio de la posición ocupada por ellos en relación a la demanda del niño.

Palabras clave: entrevistas preliminares; psicoanálisis con niños; inicio do tratamiento; síntoma en el niño; escucha a padres.

\section{Introdução}

\section{Entrevistas preliminares}

Freud (1990a) propunha que se fizesse um tratamento de ensaio antes de empreender o tratamento psicanalítico propriamente dito. Esse tinha como função estabelecer a transferência e construir uma possibilidade diagnóstica que permitisse a condução do tratamento. Mais recentemente, Quinet (1991), ao debruçar-se minuciosamente sobre o tema das Entrevistas Preliminares, propõem que as mesmas possuem três funções principais delas: a função sinto-mal, a função diagnóstica e a função transferencial. A função sinto-mal estaria referida à particularização da demanda, representada pelo sintoma apresentado ao analista, e a função diagnóstica estaria relacionada à direção da cura. Já a função transferencial é tratada como a que constitui o sujeito suposto saber. Sublinhamos que, neste escrito, queremos abordar a função sinto-mal das entrevistas preliminares, ou seja, a função que se refere ao trabalho de implicação do sujeito com seu sintoma. O sintoma, até então enigmático e expropriado do eu, passa a ser questionado e endereçado àquele para quem se supõe um saber e que fará, ilusoriamente, com que se extinga. Nesse sentido, as entrevistas preliminares permitem uma torção no estatuto do sintoma como resposta a uma formação de compromisso (Freud, 1990b). Dito de outro modo, seria uma forma de recolocar um enigma ao sujeito. É na tentativa de elaboração desse enigma que a transferência vai se instalar como motor de análise, bem como fonte de resistência.

No caso do trabalho com a criança, temos algumas especificidades que devemos considerar em relação às entrevistas preliminares. As produções de Mannoni (1999) e Dolto (2010) colocam na cena psicanalítica da época os efeitos da fantasmática parental no aparecimento da sintomatologia do filho. Desde então, tem sido considerado o encontro do psicanalista com a criança algo singular, pois na presença de uma escuta desvinculada de um ideal social da criança, revela-se algo - muitas vezes o filho é depositário de conflitos infantis dos pais e que se revelam sob a forma de sintoma na criança (Araújo, 2001; Flesler, 2012; Mannoni, 2004; Oliveira, 1996; Sei, Souza, \& Arruda, 2008; Wiles \& Ferrari, 2015; Zornig, 2000). Portanto, o percurso de entrada em análise permitiria que a criança fosse liberada do peso das histórias de seus progenitores, tornando-se possível responder, desde uma posição singular, às possibilidades de seu vir-a-ser. Importa sublinhar que tais ponderações não significam que a criança seja 
uma vítima passiva da história parental. É preciso considerar o que há do desejo da criança que a faz capturar, dentre tudo o que lhe é disponibilizado, alguns aspectos que ela pretende dar conta (Bernardino, 2004). De todo modo, geralmente, quem se queixa do sintoma não é a criança, e sim seus outros: pais, educadores, cuidadores. Lévy (2008) sugere, por exemplo, que a queixa pela sintomatologia da criança atualiza, nos pais e/ou responsáveis que se queixam, a fenda aberta quando da vivência da castração em seu próprio processo constitutivo. A atualização ocorreria, nesse segundo tempo, a partir do momento que o filho, com o seu sintoma, confronta os pais para a impossibilidade de satisfação narcísica plena, ilusoriamente construída quando do projeto do filho (Ferrari, 2012). Nesse aspecto, a função sinto-mal (Quinet, 1991) ocupa um lugar privilegiado na economia parental e, consequentemente, na demanda de análise para o filho. Hamad (2001) refere três tempos do pedido dos pais, dirigido ao analista, para atendimento da criança. O primeiro diz respeito a um desconhecimento, algo que, em função do surgimento do sintoma no filho, se torna inacessível. Em um segundo tempo, o autor relata que, não raro, emerge um conflito entre o casal, principalmente sobre a maneira de educar o filho. Sucede a esse o reconhecimento de um dos pais no sintoma do filho, desvelando, nesse movimento, a criança que não cresceu.

Considerando esses aspectos, é fundamental atentar para as tessituras discursivas que circundam a queixa dos pais pelo sintoma da criança e seu processo de implicação no trabalho terapêutico. Apostamos que a escuta pacienciosa daquele que pede atendimento pela criança pode deslocar a queixa para uma pergunta a partir da qual o filho pode passar a ser situado como sujeito de desejo. Para pensar a necessidade de um trabalho prévio ao tratamento, discorreremos sobre entrevistas preliminares realizadas com uma mãe que pede medicação para controlar o comportamento do filho na escola.

\section{Método}

\section{Participantes}

Com o intuito de refletir sobre a importância da escuta dos pais para o início do tratamento de uma criança, relataremos as entrevistas preliminares realizadas com uma mãe que buscou atendimento na Clínica da Universidade, para seu filho de 6 anos, por demanda da escola. Cabe ressaltar que recortaremos o caso em aquilo que se refira aos efeitos da rememoração de situações infantis da mãe no surgimento da função sinto-mal da queixa apresentada. Considerando que o caso foi construído em uma relação transferencial, os aspectos característicos da pessoa, como a repetição e o detalhamento de algumas histórias contadas, transparecem no relato. Todos os dados que pudessem identificar o paciente e sua família foram modificados.

\section{Procedimentos}

Depois de ter entrevistado a mãe e a criança conjuntamente, optou-se por escutar somente a mãe, a fim de trabalhar a queixa trazida, circunscrita a uma reclamação da 
professora, e a possível transformação em demanda de atendimento. Apesar de também termos conversado com o pai, trazemos somente as entrevistas realizadas com a mãe, de modo a pensar como, às vezes, o trabalho de reminiscências parentais se faz necessário para que a função sinto-mal (Quinet, 1991) surja nos pais e permita, a partir disso, o acesso da criança a seu tratamento.

Cabe ressaltar ainda que as entrevistas relatadas foram conduzidas com a primeira autora deste trabalho e coordenadora do projeto de pesquisa "Sintoma da criança: colocação em cena do infantil parental?". ${ }^{2}$ As entrevistas realizadas foram discutidas no âmbito do grupo de pesquisa com a segunda e a terceira autoras. As transcrições literais das falas da mãe se encontram em aspas. Para fins deste trabalho, optamos por relatar as entrevistas com a mãe seguindo o fluxo associativo de seu discurso. Pensamos que esse formato de escrita permite, por um lado, discutir a especificidade do caso e, por outro, transmitir a importância da escuta daqueles que se queixam de uma criança. As identidades da mãe e da criança, bem como de alguma situação que pudessem identificá-las, foram modificadas.

\section{Resultados}

\section{Fragmentos das entrevistas com a mãe}

Raquel procura atendimento para o filho, Eduardo Wellington, de 6 anos, por queixa de hiperatividade. Conta que a professora reclama que ele não faz os trabalhos em sala de aula, demandando atenção exclusiva. É a primeira vez que tem queixas do filho.

Ela chama o filho de Wellington. Essa era sua escolha, mas o pai queria que se chamasse como ele - "Eduardo José". Ficou Eduardo Wellington, para não "descontentar nem um nem outro". Raquel faz confusões com a temporalidade dos eventos, não deixando claro, por exemplo, quanto tempo de relacionamento tinha com o pai de Eduardo Wellington quando ela engravidou, há quanto tempo trabalhava no mesmo lugar, com que idade o filho passou a acompanhá-la ao trabalho, a frequentar a creche ou ainda que idade o filho tinha quando ela se separou ou quando sofreu uma internação de quase dois meses. Antes de iniciar o ensino fundamental, Wellington frequentou três creches e atualmente o menino passa um turno na escola e o outro com ela em seu trabalho em uma casa de família.

Conta morar com o filho em Porto Alegre. A família dela é do interior, mas ela veio para a capital trabalhar quando tinha 16 anos. Relata que a separação do pai de Wellington foi muito difícil. Quando se separou, continuava gostando dele e se vingava não deixando que Wellington o visse. Situa a separação ora aos quatro anos do menino, ora aos três, ora ao um ano e meio.

Quando Wellington tinha um ano e meio, ela ficou hospitalizada por dois meses. Durante esse período, não permitiu que o filho a visitasse, entrou em "depressão" por

2 Projeto n²0723, aprovado em 06 de junho de 2011 pelo Comitê de Ética do Instituto de Psicologia da UFRGS. 
falta de dinheiro e por desconfiar que o marido a traía com outra mulher. Wellington ficou aos cuidados de sua irmã. Quando saiu do hospital, estava desgostosa com o marido e passou a se dedicar ao menino. Conta que o casamento já estava afundando quando ficou grávida de Wellington.

Como gosta muito de trabalhar, começou aos 11 anos, pois queria ter o próprio dinheiro. Fala que o pai era muito autoritário e determinava até o tipo de "calcinha" que ela podia usar.

Finaliza essa entrevista dizendo que quer estabilizar o comportamento do filho para "quando atingir a idade da adolescência, sei lá, ele teje mais calmo, assim, porque no momento que ele tá assim e se ele continuá assim, a adolescência já tem mudança, aí eu sozinha vai ficá difícil pra controlá..." (sic.).

$\mathrm{Na}$ segunda entrevista, começa se queixando das cobranças da escola diante do comportamento do filho. Comenta que ele é muito dissimulado, porque nos atendimentos e na sala de espera da clínica Wellington não é inquieto, mas que em casa e na escola, sim. Queixa-se que ele nunca faz os temas, que é ela quem os faz e que, se ela não os fizesse, a escola reclamaria mais, o que a deixaria mais incomodada. Tem de ficar controlando o filho constantemente apesar de ele ter tudo para brincar, tanto em sua casa quanto no trabalho da mãe, mas ele não brinca. Com relação à própria infância, descreve-se moleca. Tinha de brincar sozinha no pátio de casa porque o pai não permitia que fosse brincar na rua. Até os 10 anos, brincou bastante, depois foi preciso ajudar os pais. Apanhou bastante do pai, muito mais que seus irmãos homens, isso porque ela falava o que vinha à cabeça e o pai achava que era falta de respeito. Tem uma cicatriz da vez em que mais apanhou. Apanhou muito de coturno, não sabe como ela pode ter filho. A mãe dela não fazia nada, era submissa. O seu inferno iniciou quando descobriu um bilhete de amor escrito por uma mulher para seu pai. Ela tinha 7 anos e o leu para a mãe, que era analfabeta. Achou que a mãe teria uma "atitude", mas não fez nada. Além de não aceitar ser mandada, nasceu com "espírito de dança", mas o pai não a deixava ir às matinês com a família vizinha. Um dia, fugiu com uma amiga adulta e foi ao baile de noite. Foi por esse motivo que saiu de casa tão cedo - se ela não fosse embora, "ia matar" seu pai, que a fez passar por muita coisa. Durante os primeiros anos longe de casa sentiu muita saudade de sua mãe. Em função do que passou na infância e na adolescência, dá "tudo para o Wellington", pois ela não pode fazer com o filho o que seu pai fez com ela em sua juventude. Termina a entrevista brava dizendo que não quer falar "das coisas ruins", que não levam a nada, só a deixam "perturbada no serviço".

Raquel retorna à clínica 15 dias depois. Conta que no fim de semana foi a primeira vez que levou o filho para andar de bicicleta e que ela ficou conversando com uma vizinha. Onde eles moram tem muito tráfico, então ela quer se mudar e os patrões se propuseram a ajudar. Não quer falar mais sobre a infância dela. Ela fica muito irritada, prefere nem pensar. Como teve de comentar, ficou irritada. Quer resolver o problema do Wellington que tem "hiperatividade" e não sabe de onde surgiu esse problema. 
Desde "nenezinho foi cheio de querer", mas nas creches nunca reclamaram dele. As reclamações começaram a aparecer agora no colégio, porque ele não faz as tarefas. 0 que a incomoda muito é o fato de a professora reclamar dele. Não sabe dizer como era quando bebê, porque frequenta creche desde os dois meses. Mas sempre foi mais inquieto. Mas ela também não sabe porque é filho único.

Ela relata que é muito sobrecarregada e Wellington é uma criança difícil. Sabe que quem tem hiperatividade e que poderia se concentrar e fazer as tarefas "se tomar um remedinho". Quer que um neurologista Ihe diga o que ele tem. Confessa que veio à clínica para que nós a encaminhássemos a um neurologista que medicasse o menino. Já levou ele a uma consulta neurológica no ano anterior, mas a médica disse que nos exames não apareceu nada. Fica brava quando digo que não temos neurologista na equipe que possa avaliar o filho. Refere, incomodada, que não é ela quem tem problema, é o filho, ela não tem motivo para conversar tanto com uma psicóloga. É o filho que lhe traz problemas quando a professora reclama dele. Por isso, quer medicá-lo. Sabe que é uma medicação que dura quatro horas - o tempo do turno escolar. Assim, a professora não se queixaria e ela estaria bem. Além disso, não é ela que tem de entrar no ritmo do filho, e sim o filho no dela. Em seguida, conta que levou o filho duas vezes ao posto, foi encaminhada ao neurologista e, nas duas avaliações, não prescreveram a medicação que ela queria. Ela quer resolver o problema do filho, e a única solução possível para ela é a prescrição de "ritalina". Na esteira disso, comenta que uma psicóloga uma vez lhe disse que certamente o menino tinha algo porque tinha "o número cinco" na carteira de bebê dele (supusemos que fosse o teste de Apgar). Mas ela não soube dizer como foi o parto, porque não se lembra de nada em função da anestesia geral. Também não soube explicar o motivo de o parto ter sido cesárea. Só sabe que o bebê teve de ir para o oxigênio. Nasceu de oito meses. Volta ao assunto da mudança de casa. Está se mudando em função do filho porque em alguns anos não poderá controlá-lo em relação ao tráfico. Quando finalizamos a entrevista, agradece.

Na entrevista seguinte, sua última, Raquel chegou com um aspecto feliz, apesar de dizer que estava cansada. Contou que tinha comprado a casa que tanto queria, sendo muito importante para ela ter saído do "beco" e ser "moradora de frente". Ficou mais perto do trabalho e da escola do filho. Wellington já fez amizade com as crianças da rua, mas também já ficou de castigo. Ela o deixou sair de bicicleta desde que andasse somente na calçada. Raquel ficou arrumando as coisas na casa e ouviu o vizinho gritar o nome do filho. Quando ela saiu, o vizinho lhe contou que o caminhão do gás quase atropelou o menino. Vai ficar duas semanas sem andar de bicicleta por ter desobedecido.

Estão para iniciar as férias escolares e, às vezes, acha que ele está mais tranquilo. Vai procurar neurologista assim que se organizar com a casa e se cadastrar no posto de saúde de seu bairro. Comento que Wellington iniciará seu tratamento em março e que ela também poderia ter um acompanhamento se assim o desejasse. Ela não se opõe e ainda refere que gostaria, já que nossas conversas têm lhe feito bem. Afirma 
que "toda ajuda é bem-vinda". Os dois iniciam seus respectivos trabalhos psicoterapêuticos, e o menino passa também a ter acompanhamento neurológico que ela procurou no posto de saúde.

\section{Discussão do caso}

\section{Finalizando para iniciar...}

A opção de seguir a cadeia associativa de Raquel para o relato das entrevistas nos permitiu colocar em discussão a importância das entrevistas preliminares com aquele que leva uma criança para atendimento. Esse formato possibilita desvendar a sequência da cadeia associativa que enlaça a história infantil parental e a queixa sobre a sintomatologia do filho. Pensando nessa cadeia, podemos vislumbrar algumas torções discursivas importantes que se refletiram em uma mudança no modo de Raquel se relacionar com o filho. Cabe ressaltar que as hipóteses levantadas na discussão desse material clínico no nosso grupo de trabalho estão enlaçadas a partir dos questionamentos da pesquisa "Sintoma da criança: colocação em cena do infantil parental?".

Primeiramente, Raquel procura o atendimento para Wellington por um encaminhamento da escola sem se implicar, ou se preocupar com esse pedido. Traz o menino porque a escola disse que era necessário. Do nosso lado, não acatando a esse pedido sem questioná-lo, propomos uma série de entrevistas com ela no intuito de transformar a queixa em demanda a partir de uma mínima implicação de Raquel em relação ao sofrimento do filho. Como não aceitamos prontamente a criança em atendimento, ela teve de se pôr a falar.

Inicia revelando o desconhecimento a respeito da história inicial do filho, não sabe dizer muito sobre ele. $O$ fato de não ter podido vivenciar o parto como experiência, inaugurou uma série de desencontros na relação com o filho, transformando essa relação em um cenário propício para que as lembranças traumáticas infantis dela fossem dramatizadas e condensadas.

Uma das grandes surpresas, e que nos parece ter permitido fazer uma importante modificação frente ao cuidado com o filho, foram as rememorações a respeito de sua infância e adolescência; as feridas não tinham cicatrizado, elas estavam tão vívidas que apesar da aparente indiferença se encarnavam na dificuldade de Raquel se adaptar às necessidades do filho. Da dificuldade de situar a história de Wellington, surgiram rememorações de violência e descaso com as quais ela teve que lidar.

A impossibilidade de se colocar em um lugar de cuidadora do filho possivelmente se enraíze no seu drama infantil e na dificuldade de situar-se em um lugar de filiação diante da mãe submissa, que não a defendia, e um pai autoritário, que determinava até as roupas íntimas que ela podia usar. As identificações necessárias com uma mãe cuidadora, que permitiriam a transformação subjetiva do lugar de filha para o lugar de mãe, pareciam estar suspensas na relação com seu filho. Não conseguiu situar um lugar de cuidado em relação ao filho possivelmente porque desde muito cedo ela teve 
de se cuidar. Não tendo encontrado ancoragem para dividir seus dramas constitutivos com algum adulto que lhe oferecesse uma contenção, não soube o que fazer quando o filho começou a lhe demandar outras coisas além dos objetos que ela podia comprar. Nesse sentido, assim como ela se colocou como porta-voz da mãe, coloca o filho como seu porta-voz na relação com o ex-marido, quiçá em uma tentativa de elaboração de seus dramas infantis.

$\mathrm{Na}$ esteira dessa lembrança, podemos construir uma hipótese sobre a dificuldade que ela tem em se relacionar com Wellington desde um lugar de maternal de cuidado. Assim como ela, o filho foi colocado no lugar de revelar e testemunhar a traição sofrida. Ao mesmo tempo, o pedido de que o filho não fosse vê-la quando ela foi hospitalizada pode manifestar uma ressignificação do momento que ela teve que sair precocemente de sua casa e viu-se impedida de ter sua mãe por perto. Uma mãe não pode ser vista frágil ou submissa, o preço que ela pagou por isso foi alto demais e não permitiu que o filho passasse pela mesma experiência. No enlace de tudo isso, surge também a mágoa que ela tem da mãe por não a ter defendido das surras do pai; a mãe não cuidou da filha da maneira como ela almejava. Como esperar uma posição de cuidado se ela ficou à mercê da fúria de um pai que a espancava a ponto de deixar marcas no corpo? Novamente uma dupla identificação parece se precipitar nessas lembranças - a necessidade que ela teve de sair muito cedo de casa e o imperativo que ela própria colocou de que o filho não a visitasse no hospital para não a encontrar fragilizada assim como sua mãe.

Em vários momentos, Raquel refere que precisa controlar o filho antes de chegar à adolescência. Falando de sua vinda para a capital, conta com muita dor que se ela não saísse de casa, ela mataria seu pai pela violência sofrida, pois não se submetia às exigências dele sem questioná-las. O que disso retorna na relação com Wellington às vésperas da adolescência do menino? O que se antecipa como ponto de chegada seriam os questionamentos do filho ao seu controle e a consequente solidão pelo abandono? Já não serão "só os dois", ela voltará a ser só ela.

As questões aqui elencadas são uma pequena parte do que foi suscitado por esse caso nas discussões no grupo de pesquisa. A escolha pelos fragmentos aqui reproduzidos nos permitiu refletir sobre a importância da escuta dos adultos que levam uma criança para atendimento. A partir do momento que se propõe uma escuta para Raquel como mãe de Wellington, é possível uma torção de olhar: ela coloca em cena seu sofrimento e abre a porta para o filho aparecer como sujeito, passa a se disponibilizar no cuidado do filho.

As entrevistas realizadas com Raquel quiçá tenham permitido construir outro destino para o sofrimento próprio e do filho. O percurso de Raquel por sua história permitiu começar a se perguntar sobre o filho e, consequentemente, sobre sua maternidade. Os dramáticos eventos da sua infância e adolescência, que passamos a testemunhar, começam a desfazer os nós que estavam encarnados nas reclamações da escola a respeito do filho. As lembranças que foram surgindo, de forma quase catárti- 
ca, permitiram tecer hipóteses explicativas a respeito do sofrimento de Wellington e de Raquel. De total descomprometimento a respeito das dificuldades de Wellington, passamos a testemunhar uma mudança de disponibilidade frente à problemática do filho. A dificuldade de Raquel de poder se adaptar às necessidades do filho possuem raízes muito arcaicas. A posteriori, pode ser trabalhada a solidão sofrida quando das surras e da descoberta da traição do pai, da submissão da mãe e da impossibilidade da mãe de defendê-la, da traição de seu marido, a saudade da mãe quando veio morar na cidade e a saudade do filho quando ficou hospitalizada, entre outras tantas cenas de sofrimento relatadas. Esses eventos se precipitaram no corpo do filho em uma tessitura de expectativas de encontros frustrados - a mãe que não a acolheu, o marido que a traiu, o filho que ela não pode cuidar...

Considerar as reminiscências trazidas por Raquel a respeito de sua infância e adolescência permitiu que as representações, que estavam sendo transferidas para a relação com seu filho, pudessem ser deslocadas. Nesse movimento, de uma total indiferença frente à queixa do filho, passa a reclamar que o problema de Wellington a incomoda porque a escola se queixa para ela. Essa reclamação vem acompanhada de um pedido de esbatimento do sintoma. Como esse pedido não foi acatado, ela fica brava, mas a incidência de uma fenda permite o surgimento da função sinto-mal (Quinet, 1991) em relação à manifestação sintomática do filho.

Pensamos que o não acolhimento literal do pedido de conformidade do filho em relação ao ideal parental interroga o seu saber imaginário totalizante e permite que os questionamentos sobre as necessidades do filho surjam. Acontece um deslocamento do "tem tudo o que ele quer" para a necessidade de encontrar outro lugar mais adequado para um futuro adolescente morar. Na trilha desse caminho que se inicia, vislumbra em Wellington um sujeito que, à medida que cresce, tem diferentes necessidades para além dos objetos que ela pode comprar. Pelo não acolhimento literal de um pedido de conformidade, mas pelo acolhimento dela como mãe, faz uma tentativa de enxergar o filho como alguém que precisa de sua proteção, proteção esta que Ihe foi negada quando ela era criança. Foi necessário permitir o surgimento da criança que não cresceu nela (Hamad, 2001) para ela pudesse se ocupar do filho. Nesse percurso, faz um movimento concreto na sua vida cotidiana. Muda-se de bairro em função de uma necessidade que percebe no filho e uma disponibilidade que ela passa a ter agora pode cuidá-lo e lhe oferecer um lugar menos perigoso para crescer. Wellington pode fazer amigos, andar de bicicleta e ser colocado de castigo porque se expôs ao perigo. Raquel acabou por aceitar o tratamento para o filho e uma escuta para ela, a fim de ser ajudada na relação com essa criança - o filho, mas também a que ainda resta nela.

Possivelmente, sem a escuta de Raquel como mãe de Wellington o início do trabaIho clínico com o filho não tivesse acontecido. Talvez ela continuasse, incessantemente, a busca pela receita de "ritalina" que extirpasse a queixa da escola frente à inquietude de Wellington, impedindo a elaboração de um passado de dores, traições e 
descasos. Assim, como lembra Lévy (2008), muitas vezes o sintoma da criança tem uma função estruturante para um dos pais. Considerando que, na chegada de um filho, há uma atualização do momento constitutivo da castração parental e, em havendo fraturas no recalcamento, podemos supor que o filho pode ser utilizado como palco onde se atuam as tragédias de sua própria filiação (Ferrari, 2012). Sem o dispositivo da escuta pacienciosa e atenta de Raquel sobre sua história, é possível que o enigma do sintoma de Wellington não tivesse aparecido, impedindo a construção e sustentação de uma demanda na direção de um sujeito suposto saber acerca do sofrimento que estava em questão no sintoma do filho.

\section{Conclusão}

Pensamos que a escuta dos pais em Entrevistas Preliminares pode ser um dispositivo potente, especialmente no que se refere a possibilitar uma operação de elaboração do recalcamento infantil fraturado dos pais que pode ter se precipitado quando da chegada de um filho. No momento em que as rememorações parentais encontram outra guarida, abre-se o espaço necessário para que a criança possa despojar-se do que não lhe pertence e passar a assumir os próprios dramas constitutivos. Acreditamos que, quando a sintomatologia da criança está tão contaminada pela história infantil parental, a escuta dos pais viabiliza que o trabalho com a criança aconteça. Assim, o enigma do sintoma trazido pela criança pode ser enlaçado à história infantil daquele que se queixa precipitando a função sinto-mal e a consequente implicação dos pais no sofrimento da criança.

\section{Referências}

Araújo, M. L. (2001). O discurso dos pais na clínica psicanalítica com crianças: significantes transgeracionais em questão. Colóquio do LEPSI IPIFE-USP, São Paulo, SP, Brasil, 3. Recuperado em 27 fevereiro, 2017, de http://www.proceedings.scielo.br/ scielo.php?script=sci_arttext \&pid=MSC0000000032001000300025\&lng=en\&nrm= abn.

Bernardino, L. (2004). As psicoses não decididas na infância. São Paulo: Casa do Psicólogo.

Dolto, F. (2010). A imagem inconsciente do corpo. São Paulo: Perspectiva.

Ferrari, A. G. (2012, dezembro). Sintoma da criança, atualização do processo constitutivo parental?. Tempo psicanalítico, 44(2), 299-319.

Flesler, A. (2012). A psicanálise de crianças e o lugar dos pais. Rio de Janeiro: Zahar.

Freud, S. (1990a). Sobre la dinámica de la trasferencia. In J. Strachey (Org.). Obras completas (pp. 93-106). Buenos Aires: Amorrortu. (Trabalho original publicado em 1912). 
Freud, S. (1990b). Inhibición, sintoma y angustia. In J. Strachey (Org.). Obras completas (pp. 71-161). Buenos Aires: Amorrortu. (Trabalho original publicado em 1925).

Hamad, N. (2001). A psicanálise com crianças entre Freud e Lacan. In M. C. Vidal (Org.). Quando chega ao final a análise com uma criança? (pp. 129-144). Salvador: Ágalma.

Lévy, R. (2008). O infantil na psicanálise, o que entendemos por sintoma na criança. Rio de Janeiro: Vozes.

Mannoni, M. (1999). A criança, sua doença e os outros. São Paulo: Via Lettera.

Mannoni, M. (2004). A primeira entrevista em psicanálise. Rio de Janeiro: Elsevier.

Oliveira, L. G. M. de. (1996). A transferência no trabalho com os pais na instituição. Estilos da Clinica, 1(1), 34-45. Recuperado em 27 fevereiro, 2017, de http://pepsic. bvsalud.org/scielo.php?script=sci_arttext\&pid=\$1415-71281996000100004\&lng= pt\&tlng=pt.

Quinet, A. (1991). As 4+1 Condições da Análise. Rio de Janeiro: Zahar.

Sei, M. B., Souza, C. G. P., \& Arruda, S. L. S. (2008). O sintoma da criança e a dinâmica familiar: orientação de pais na psicoterapia infantil. Vínculo, 5(2), 194-207. Recuperado em 27 fevereiro, 2017, de http://pepsic.bvsalud.org/scielo. php?script=sci_arttext\&pid=S1806-24902008000200009\&lng=pt\&tIng=pt.

Wiles, J. M., \& Ferrari, A. G. (2015). Clínica nos bastidores: o trabalho com os pais na clínica psicanalítica com crianças. Psicologia Clínica, 27(2), 103-119. Recuperado em 27 fevereiro, 2017, de http://pepsic.bvsalud.org/scielo.php?script=sci_ arttext\&pid=S0103-56652015000200006\&lng=pt\&tlng=pt.

Zornig, S. (2000). A criança e o infantil em psicanálise. São Paulo: Escuta.

Submissão: 12.9 .2016

Aceitação: 9.3.2017 